\title{
Um experimento para compreender como os aspectos afetivos podem ser reconhecidos em ambientes virtuais de aprendizagem
}

\author{
Magalí Teresinha Longhi \\ Daniela Forgiarini Pereira \\ Magda Bercht \\ Patricia Alejandra Behar \\ Programa de Pós-Graduação em Informática na Educação \\ Universidade Federal do Rio Grande do Sul (UFRGS) \\ Caixa Postal 5071 - 90.041-970 - Porto Alegre - RS - Brasil \\ mlonghi@cesup.ufrgs.br, dfpr@terra.com.br, bercht@inf.ufrgs.br, \\ pbehar@terra.com.br
}

Resumo: Este artigo apresenta um estudo de caso realizado a partir da aplicação do objeto de aprendizagem AnimA-K para validar o modelo de estados afetivos dos alunos. O modelo, baseado na teoria de appraisal de Scherer, foi elaborado para inferir os estados de ânimo durante o processo de aprendizagem mediado por ambientes virtuais de ensino e aprendizagem. $\mathrm{O}$ experimento considera as interações dos alunos com o objeto de aprendizagem e analisa os comentários registrados na ferramenta Fórum. A representação formal adotada e os resultados obtidos são abordados.

Palavras-chave: Reconhecimento de emoções, estado de ânimo, objeto de aprendizagem, ambientes virtuais de aprendizagem

\section{An experiment to understand how the affective aspects can be detected in virtual learning environments}

Abstract: We present the learning object AnimA-K as a case study to validate the affective model of students. The model is based on the appraisal theory proposed by Scherer, and it was prepared to infer mood during the learning process mediated by virtual learning environments. The experiment considers the interactions of students with the object and analyzes the comments recorded in Forum tool. The computational formalization adopted and the partial results are mentioned at this paper.

Key-words: Affective recognition, mood, learning object, virtual learning environments

\section{Introdução}

A Computação Afetiva aplicada à Educação vem contribuindo para o desenvolvimento de "tutores virtuais", "companheiros virtuais de aprendizagem" e outros assistentes virtuais, os quais percebem as reações afetivas do aluno, "raciocinam" sobre elas e comportam-se afetivamente para apoiar o aprendizado. Estudos (Bercht 2001; Rodrigues \& Carvalho, 2005; Jaques et al., 2009) demonstram que o reconhecimento dos aspectos afetivos e sua aplicação em agentes virtuais, principalmente em sistemas tutores inteligentes (STI), resultam em sistemas adaptativos e funcionalmente mais eficientes.

Em relação às investigações sobre ambientes virtuais de ensino e aprendizagem (AVA) ${ }^{1}$, onde os participantes atuam num espaço de ordem e desordem, de forma linear e não-linear, de cooperação e colaboração (Behar et al. 2005), pouca atenção tem sido conferida ao estudo da afetividade nas interações estabelecidas nos diversos nívies. Pesquisas na área da Computação Afetiva vêm sendo direcionadas para detectar o estado afetivo e a atenção do aluno (como por exemplo, análise da voz e de expressões faciais, 
rastreamento dos olhos, condutividade da pele, posicionamento e modo como o aluno interage com o ambiente). Desta forma, aplicações educacionais "sensíveis social/afetivamente" revelam-se capazes de exibir os conteúdos de acordo com a receptividade do aluno no momento da aprendizagem. Apresentam resultados mais promissores do que investigações por meio de perfis ou preferências informados e/ou estilos de aprendizagem previamente reconhecidos.

Os estudos teóricos sobre a definição de afetividade (especialmente a de estados de ânimo) fundamentam o mapeamento dos aspectos afetivos capazes de serem observados por um agente artificial durante a interação do aluno com um objeto de aprendizagem disponibilizado em um AVA.

Parte-se da noção que a aprendizagem é, essencialmente, um processo que envolve as dimensões cognitiva, conativa (motivação e volição) e afetiva (Eynde et al., 2007). Para explicar, a natureza do fenômeno afetivo experimentado reconhecendo as relações complexas entre os processos cognitivos e conativos, emprega-se a teoria de appraisal, baseada em um sistema de componentes afetivos proposto por Scherer (2001).

No modelo de Scherer, o processo de avaliação cognitiva (appraisal) de um fenômeno afetivo é contínuo. As mudanças (comportamentais, fisiológicas, etc.) ocorrem em resposta à avaliação de estímulos, eventos ou alterações no próprio organismo, de modo inter-relacionado e interindependente. A emoção é descrita como um "dispositivo sintonizador", constituído por cinco componentes (cognitivo, fisiológico, motivacional, expressão motora e de sentimento subjetivo) com funções específicas nos subsistemas orgânicos correspondentes, que, de forma constante e dinâmica, verifica e ajusta as mudanças afetivas através de um contínuo monitoramento do ambiente físico e social. Logo, a emoção é percebida como um processo de sincronização desses componentes.

A afetividade é um termo geral que relaciona fenômenos psíquicos e físicos incluídos nas experiências afetivas. Assim, os termos: emoção, estados de ânimo, sentimento, motivação, personalidade, temperamento e outros tantos estão relacionados à afetividade. A emoção é definida como um fenômeno ocasional, de alta intensidade e breve duração, em que é possível perceber seu começo e fim, sendo caracterizada como um processo dinâmico. Já o estado de ânimo é difuso, de baixa intensidade e longa duração, podendo não ter causa conhecida (Scherer, 2005). Na língua portuguesa, existem diferenças semânticas entre as expressões "ter/sentir ansiedade" e "ser/estar ansioso". A primeira refere-se a uma emoção, e significa que o sujeito tem ou sente ânsia, aflição ou angústia por algo, alguém ou evento que aconteceu. A segunda indica que o sujeito encontra-se em um estado de ânimo relacionado à emoção experimentada (ou outras disparadas concomitantemente).

$\mathrm{Na}$ psicologia educacional, a ansiedade é a emoção mais estudada (Schutz \& Pekrun, 2007). Pesquisas empíricas sobre a ansiedade dos alunos, conduzidas há mais de 50 anos, apresentam evidências sobre sua estrutura, medidas, exame dos fatores que a desencadearam e suas implicações na aprendizagem. Já no âmbito da aprendizagem organizacional, Tran (2004) chegou à conclusão ser mais conveniente o exame dos estados de ânimo, pois são fenômenos afetivos mais representativos do cotidiano e, portanto, mais fáceis de medir. Nesse sentido, Davidson (1994) afirma que a emoção influencia o comportamento, enquanto o estado de ânimo influencia a cognição.

Por outro lado, as tecnologias digitais motivam o aperfeiçoamento de recursos educacionais, capazes de serem disponibilizados e acessados de qualquer lugar, a qualquer momento. É de consenso na literatura que os recursos educacionais conhecidos como objetos de aprendizagem, ao serem projetados de forma digital com a característica de interatividade, permitem que o aluno tenha um papel ativo na construção de seu conhecimento. 
Os objetos de aprendizagem proporcionaram novas oportunidades para a EAD. Eles podem ser compartilhados por várias instituições através dos repositórios de armazenamento (a exemplo do RIVED, suportado pela SEED/MEC; CESTA, pela UFRGS; e MERLOT, pela Universidade da Califórnia, pioneira na construção de repositórios). Esses recursos educacionais abertos criaram um novo conceito de EAD: as universidades abertas ${ }^{2}$ (dos Santos, 2009).

Com o propósito de avaliar a possibilidade de reconhecer os estados de ânimo caracterizados pelos termos animado/desanimado e satisfeito/insatisfeito, desenvolveu-se o objeto de aprendizagem AnimA-K para o conteúdo construção de algoritmos aplicável em disciplinas que tratam da lógica de programação. Este artigo aborda um estudo de caso efetuado durante a aplicação do AnimA-K em uma disciplina do curso Ciência da Computação (UFRGS). Na próxima seção, faz-se uma breve descrição do referencial teórico utilizado para embasar a representação dos estados de ânimo em análise. Na Seção 3, o objeto de aprendizagem AnimA-K é apresentado. Na Seção 4, indica-se o método e os indicadores utilizados; enquanto que na Seção 5, é relatado o estudo de caso e os resultados parciais obtidos. Finalmente, na Seção 6, são feitas algumas considerações finais apresentando os próximos desafios.

\section{Mapeamento dos estados de ânimo}

Scherer e Tran (2001) descreveram o impacto de algumas emoções no processo de aprendizagem em organizações, determinando quais delas têm influência mais decisiva nos processos de tomada de decisão. As emoções que podem caracterizar determinados estados de ânimo são classificadas em famílias afetivas, sendo posicionadas em um espaço de representação, conforme apresentado na Figura 1. As famílias afetivas são rótulos para um grupo de emoções, reunidas com base em extenso estudo teórico, e justificativas empíricas.

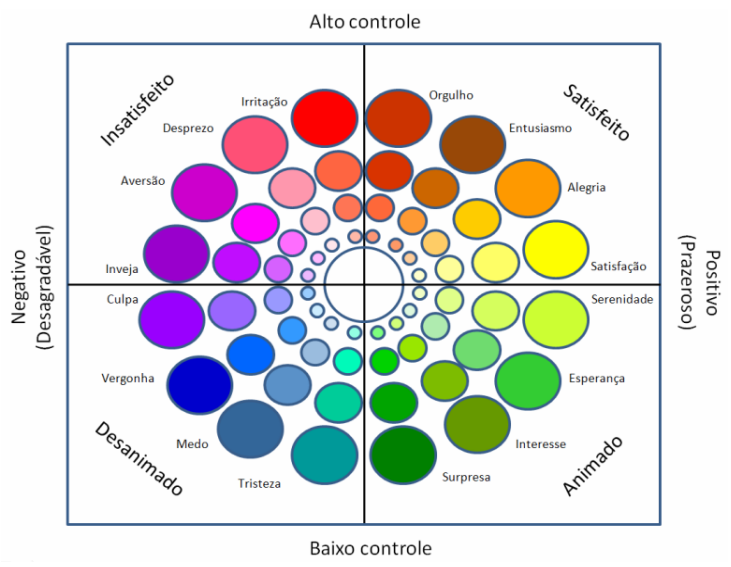

Figura 1. Espaço de representação dos estados de ânimo (Tran, 2004)

Neste trabalho, são consideradas quatro classes de estados de ânimo, baseadas principamente nas definições de Scherer (2005) e Tran (2004):

(1) Animado - implica demonstrar (ou não) surpresa, interesse, esperança e serenidade para enfrentar os desafios da aprendizagem, colaborando e cooperando com os colegas. É composto por emoções condutivas, aquelas que imbuem o aluno de ânimo positivo para explorar, desenvolver e continuar o aprendizado. Podem, entretanto, ter conotação negativa, por exemplo, estar demais interessado pode induzi-lo a uma dispersão de atenção e energia, ter foco difuso e/ou criar planos impraticáveis.

(2) Desanimado - implica demonstrar (ou não) tristeza, medo, vergonha e culpa por não conseguir acompanhar o conteúdo. É composto por emoções resignativas, 
aquelas que podem levar o aluno a desistir do processo de aprendizagem. Contudo, podem ter implicações positivas, no sentido de provocar um tempo de recuperação para repensar atitudes, readaptar-se a novas condições ou previnir-se para não envolver-se novamente na mesma situação.

(3) Satisfeito - implica demonstrar (ou não) satisfação, alegria, entusiasmo e orgulho pela tarefa cumprida. É composto por emoções logrativas, aquelas que marcam a celebração do sucesso (Scherer \& Tran, 2001). Implicações negativas podem ocorrer quando em excesso.

(4) Insatisfeito - implica demonstrar (ou não) irritação, desprezo, aversão e inveja. É composto por emoções antagônicas, aquelas em que o aluno pode alimentar um desejo por represálias ou vinganças. Por outro lado, podem ter implicações positivas como, por exemplo, manter o grupo unido para atingir os objetivos e estar apto a contra-atacar por injustiças sofridas ou para enfrentar obstáculos.

O modelo de Scherer e o espaço de representação dos estados de ânimo apresentados na Figura 1 foram adotados para formalizar a pesquisa. A escolha desta teoria cognitiva se dá especialmente por considerar que os fenômenos afetivos são processos em vários componentes orgânicos, não apenas no cognitivo, como expressado em outras teorias. Empregar uma teoria de maior amplitude garante a extensão da pesquisa em outros componentes (por exemplo: aplicação em agentes afetivos animados, utilização de sensores para captura de sinais fisiológicos, compreensão do porque a escolha de uma ação, etc.). Outro motivo para a escolha está no fato de o modelo de Scherer representar as emoções num espaço contínuo e não de modo discreto como em outras teorias.

\section{O objeto de aprendizagem AnimA-K}

Para o mapeamento dos estados de ânimo do aluno, faz-se necessário o desenvolvimento de um protótipo que verifique quais aspectos afetivos podem ser identificados automaticamente. Com este objetivo, concebeu-se o protótipo AnimA ${ }^{3}$, inicialmente constituído por três objetos de aprendizagem a serem aplicados em alunos dos cursos de pós-graduação, graduação e técnico das grandes áreas de conhecimentos: Ciências Exatas e da Terra; Ciências Sociais Aplicadas; e Ciências Humanas.

Neste artigo apresenta-se o AnimA- $\mathrm{K}^{4}$, desenvolvido pela equipe do NUTED/UFRGS ${ }^{5}$. Trata-se de um objeto de aprendizagem que aborda os conceitos de lógica de programação com o objetivo de contextualizar o ensino de construção de algoritmos para alunos da graduação e técnico. Os participantes devem selecionar um exercício de lógica, da complexidade exigida, entender o problema considerando as regras impostas, e para tal, encontrar uma metodologia para solucionar o problema. Por fim, formular o algoritmo na linguagem disponibilizada pelo objeto podendo ser reescrito posteriormente em linguagem computacional.

O AnimA-K conta com quatro recursos principais: o que trata da fundamentação teórica, o das atividades ou tarefas, o dos materiais de consulta e o do perfil afetivo do aluno. O recurso a ser focalizado neste artigo é o de Atividades (Figura 2a). É nele em quem são apresentados jogos que demandam habilidades cognitivas de resolução de problemas nos diversos níveis de complexidade (básica, média e alta), onde são extraídos os dados para avaliação dos estados de ânimo do aluno.

O experimento, apresentado na seção 5, está baseado na atividade de nível básico "Pulo dos Sapos", que consiste na troca de lugares entre sapos fêmeas e machos. Os alunos devem indicar nas instruções de movimento o gênero do sapo e a pedra de salto. A interface mantém botões com opções para testar o movimento, apagar a última instrução, 
reiniciar o jogo quando o aluno chegar em um ponto sem solução e sair do jogo por desistência (Figura 2a).

Em três momentos do jogo (início, meio e fim da atividade), o aluno recebe do sistema uma interface de autorelato do seu estado de ânimo (Figura 2b). A interface foi projetada na forma de círculo, atendendo as especificações do Geneva Emotion Wheel desenvolvido pelo Swiss Center of Affective Sciences (Scherer, 2005) e apresentado na seção 2 deste artigo. A interface de autorelato é um instrumento que mede as reações emocionais sobre objetos (colegas, professores e conteúdos ou materiais), eventos e situações que se apresentam no processo de ensino e aprendizagem aqui denominada Roda dos Estados Afetivos (REA).

A REA apresenta 16 classes afetivas dispostas em círculo e representadas por um padrão de cores. Cada classe é identificada por uma palavra-rótulo e por círculos (implementados na forma de botões) de tamanhos diferentes com gradações de cores que variam de uma cor mais forte (círculo maior) para uma mais fraca (círculo menor). $\mathrm{O}$ tamanho dos círculos indica a intensidade da experiência afetiva e é definindo pela escala de medida: Muito Forte, Forte, Médio (nem forte, nem fraco), Fraco e Muito Fraco. No interior do círculo é apresentada a opção Nenhum, caso o aluno acredite não estar vivenciando algum estado afetivo ou não ter encontrado correspondência em alguma classe afetiva apresentada.

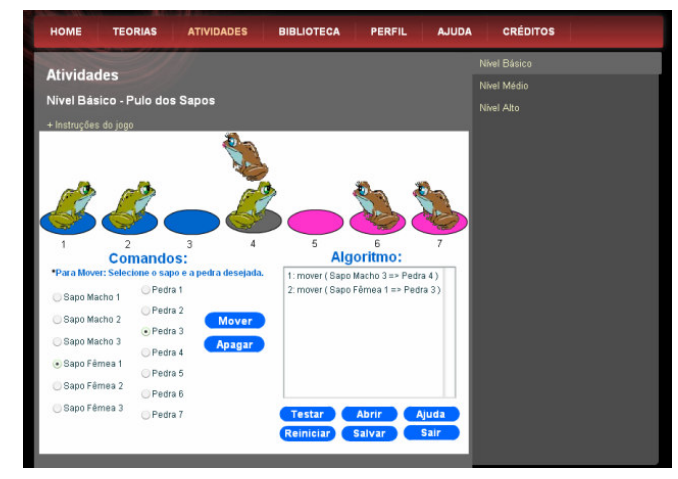

(a)



(b)

Figura 2: (a) Interface do jogo "Pulo dos Sapos" no momento da testagem; (b) Interface de autorelato.

\section{Modelos e métodos utilizados}

As etapas de aquisição, identificação e inferência compreendem a fase de reconhecimento dos estados de ânimo no AnimA-K. A etapa de Aquisição envolve os meios e os métodos através dos quais o sistema recolhe sinais ou dados processados para determinar as características cognitivas e afetivas em análise. Para tanto, são reconhecidos indicadores semiaparentes e de avaliação. Os indicadores semiaparentes são extraídos através de informações obtidas do comportamento do aluno (a saber: tempo de execução de uma atividade, número de vezes que retornou ou desistiu da atividade, sucesso ou falha na execução da atividade e pedidos de ajuda) e da expressão textual, através de adjetivos e advérbios encontrados na escrita e/ou a utilização de emoticon nos fóruns, diários de bordo e bate-papo no AVA ROODA.

Os indicadores de avaliação são obtidos através da aplicação de questionários ou inventários de pesquisa em três momentos: no início da disciplina, no começo, durante e término de uma atividade de aprendizagem. O instrumento IFP $^{6}$, inventário aplicado no início da disciplina por psicólogo autorizado, recolhe dados sobre os traços de personalidade do aluno (inclui seis variáveis de interesse: dominância, desempenho, agressão, pesistência, mudança e autonomia). O instrumento REA é utilizado para captar 
os dados de autorelato nos três momentos da atividade. $\mathrm{O}$ autorelato é utilizado para confrontar com os identificados automaticamente.

Os diversos sinais apontados passam por um sistema de reconhecimento de padrões de onde são obtidas, na etapa de Identificação, as características comportamentais, textuais e autoavaliativas do aluno, classificadas em categorias cognitivas e afetivas. Já na etapa de Inferência são construídos modelos dinâmicos e probabilísiticos possibilitando selecionar o possível estado de ânimo do aluno apresentado no decorrer da aprendizagem.

Trata-se, enfim, de identificar quais variáveis dependentes e independentes são importantes para a inferência dos estados de ânimo. Verifica-se o relacionamento do aluno no ambiente virtual através da forma como age com o objeto de aprendizagem e o AVA. Para identificar os fatores afetivos comportamentais foram adotados: o modelo de subjetividade afetiva apresentado em Kantrowitz (2003), no que se refere às manifestações escritas; e, o modelo de Bercht (2001) para os fatores confiança, independência e esforço, baseado nos estudos de Soldato \& Boulay (1995) e Serres (1993). Esses modelos são agrupados em um único conjunto denominado, neste estudo, de padrão comportamental.

O modelo de confiança indica com que grau de segurança o aluno desenvolve a atividade. A persistência na resolução de problemas determina o modelo de esforço do aluno. Já o modelo de independência é determinado pelo grau de autonomia do aluno em relação ao aprendizado.

O modelo de subjetividade afetiva é extraído dos textos registrados nas ferramentas síncronas/assíncronas do AVA. São utilizadas tecnologias de Mineração de Opinião (ou Análise de sentimentos) para identificar a opinião positiva ou negativa sobre o processo de aprendizagem de uma atividade, de um conteúdo e da própria disciplina. $\mathrm{O}$ principal desafio dessas tecnologias é determinar qual parte do texto contém material subjetivo. São aplicadas técnicas de mineração de texto, visando identificar como cada aluno se manifesta afetivamente quanto ao desempenho alcançado na execução da atividade proposta. Para a indexação é utilizada a base WordNet Affect BR (Pasqualotti, 2008), que mantém um léxico com palavras do domínio afetivo para a língua portuguesa.

O modelo afetivo do aluno é representado através de uma rede semântica, conforme ilustrado na Figura 3, relacionando os componentes afetivos do modelo de Scherer. A tecnologia de Redes Bayesinas Dinâmicas (RBD) é a abstração computacional escolhida para apropriar essa rede semântica. Tal escolha se deve ao fato de uma tecnologia adequada para descrever os aspectos de incerteza inerentes à dimensão afetiva e por tratar os aspectos dinâmicos do processo de inferência (o modelo afetivo é constantemente atualizado conforme os dados vão sendo capturados). Salienta-se que, neste estudo, enfatiza-se o componente cognitivo (appraisal cognitivo) e motivacional (estado motivacional) do modelo de Scherer.

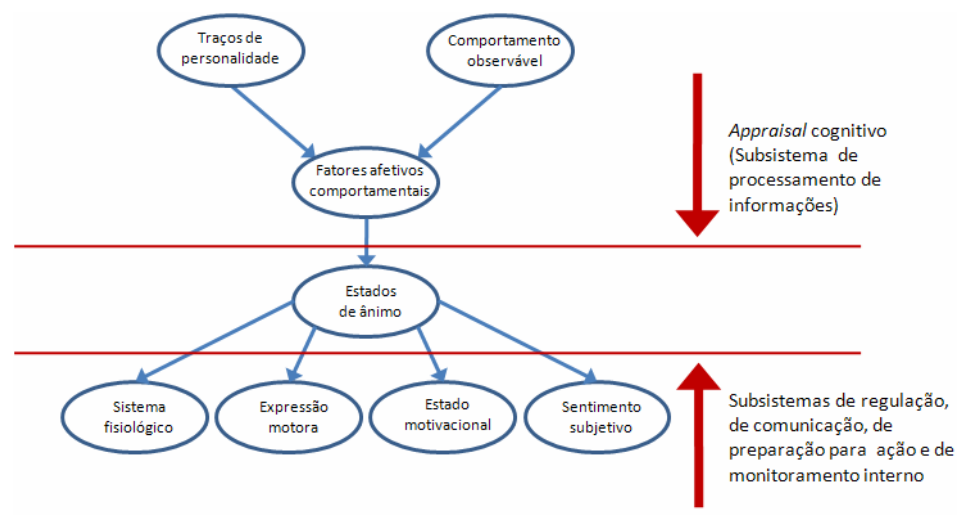

Figura 3. Classe de variáveis e relações do modelo afetivo do aluno 
$\mathrm{Na}$ RBD proposta, os traços de personalidade influenciam o padrão comportamental do aluno. Isto é, os modelos de confiança, independência, esforço e subjetividade afetiva determinam um padrão comportamental que, em conjunto com a expectativa de resultados e o resultado efetivamente alcançado, influenciam no estado de ânimo do aluno.

\section{Estudo de Caso}

O experimento consistiu em um instrumental com o objetivo de capturar dados através (a) de respostas em questionários ou inventários ${ }^{7}$, (b) da contabilização automática dos padrões comportamentais no objeto de aprendizagem e (c) dos relatos textuais no AVA. Neste estudo de caso, os alunos relataram experiências, dúvidas, etc. por meio da ferramenta Fórum ao fim do processo de aprendizagem, cujo conteúdo foi utilizado para determinar a afetividade na linguagem.

A amostra de três alunos de uma disciplina da Ciência da Computação (UFRGS) ministrada na modalidade EAD é utilizada para exemplificar e ilustrar o funcionamento do modelo proposto de inferência dos estados de ânimo apresentada nesta pesquisa.

O escore percentílico ${ }^{8}$ dos traços de personalidade é obtido a partir da apropriação das respostas dos alunos ao questionário IFP em aplicativo web após análise efetuado pelo psicólogo da equipe. Portanto, o percentil é uma evidência na RBD (Tabela 1), em que o aluno S53 tem altos níveis de percentis em relação a uma população analisada pelo instrumento IFP e não aos seus outros dois colegas. O aluno S55 tem um percentil reduzidíssimo para agressão. Isto significa que, para uma população já analisada, apenas $5 \%$ dela tem níveis de percentis inferiores a apresentada pelo aluno, enquanto $95 \%$ da população tem um grau de agressividade maior.

Tabela 1. Percentis dos traços de personalidade da amostra

\begin{tabular}{|c|c|c|c|c|c|c|}
\hline Aluno & Dominância & Desempenho & Agressão & Persistência & Mudança & Autonomia \\
\hline S53 & 97 & 100 & 65 & 95 & 85 & 92 \\
\hline S54 & 60 & 80 & 18 & 65 & 43 & 45 \\
\hline S55 & 67 & 92 & 5 & 45 & 55 & 30 \\
\hline
\end{tabular}

O comportamento observável (indicadores semiaparentes) dos alunos durante o desenvolvimento da atividade é apresentado na Tabela 2. O total de testes efetuados determina o número de vezes em que o aluno precisou testar o algoritmo para verificar se a sua lógica estava correta. $\mathrm{O}$ número de reínicios indica a quantidade de vezes que o aluno teve que reiniciar seu algoritmo ao incorrer em uma situação de falha ou sem solução. O item número de pedidos de ajuda está dividido em dois: ajuda sobre como usar a interface do jogo e sobre as regras do jogo. O item forma de conclusão da atividade demonstra a maneira como o aluno finalizou o jogo: concluindo a atividade com sucesso, desistindo da atividade ou saindo da página do jogo.

Observa-se que o aluno S53 entrou no jogo (registro 1071) e dois minutos após (registro 1073) reiniciou o jogo em nova janela, decidindo cancelá-lo logo em seguida. Todos os registros afetivos (Tabela 3) e cognitivos efetuados foram registrados na janela de registro 1071. Os registros 1072 e 1074 informam que o aluno S55 abriu duas páginas do jogo. Concluiu a atividade na página de registro 1072 e reiniciou o jogo na 1074, sem que nenhum movimento fosse assinalado.

O autorelato dos estados afetivos foi coletado em três momentos de execução da atividade (Tabela 3): no início da atividade, na sétima instrução do algoritmo (considerou-se a sétima instrução como sendo um tempo intermediário entre o início e fim do algoritmo) e ao fim (conclusão por solução ou por desistência) da atividade. Já o cálculo dos fatores comportamentais sobre os dados obtidos na Tabela 2 está apresentado 
na Tabela 4. A idéia é identificar como os fatores comportamentais influenciam nos estados de ânimo.

Os comentários sobre a atividade registrados textualmente no fórum do AVA também podem servir para identificar os estados de ânimo dos alunos. A partir dos registros textuais e após os processo de tokenização ${ }^{9}$ e eliminação das stopwords ${ }^{10}$, realizou-se a análise das palavras, verificando quais são advérbios e adjetivos. A Tabela 5 apresenta os valores normalizados para os quadrantes da REA obtidos no processo de sumarização durante a mineração subjetiva sobre os textos deixados no fórum do AVA. Observa-se que o aluno S53 não deixou suas impressões sobre a atividade realizada (Senteça=0). O aluno S54 descreveu seu comentário em apenas uma frase. Já o aluno S55, redigiu três frase para expor sua opinião. Entretanto, na última delas, não foram encontrados indícios subjetivos.

Tabela 2. Comportamento observável da amostra em análise

\begin{tabular}{|c|c|c|c|c|c|c|c|c|c|}
\hline \multirow{2}{*}{ Alund } & \multirow{2}{*}{ Reg } & \multicolumn{3}{|c|}{ Tempo } & \multirow{2}{*}{$\begin{array}{c}\text { Total de } \\
\text { testes }\end{array}$} & \multirow{2}{*}{$\begin{array}{c}\text { Número } \\
\text { de } \\
\text { reinícios }\end{array}$} & \multicolumn{2}{|c|}{ Pedidos de ajuda } & \multirow{2}{*}{$\begin{array}{c}\text { Forma de } \\
\text { conclusão da } \\
\text { atividade }\end{array}$} \\
\hline & & Início & Fim & Duração & & & $\begin{array}{r}\text { Uso } \\
\text { jogo }\end{array}$ & $\begin{array}{c}\text { Regras } \\
\text { jogo }\end{array}$ & \\
\hline S53 & 1071 & 14:41:00 & 15:10:19 & $00: 29: 19$ & 26 & 3 & 0 & 0 & Completou \\
\hline S53 & 1073 & $14: 43: 28$ & $14: 43: 34$ & 00:00:06 & 0 & 0 & 0 & 0 & $\begin{array}{l}\text { Saiu da } \\
\text { página }\end{array}$ \\
\hline S54 & 1070 & $14: 40: 50$ & $14: 54: 46$ & $00: 13: 47$ & 13 & 0 & 0 & 0 & Completou \\
\hline S55 & 1072 & 14:41:00 & $14: 54: 25$ & $00: 13: 25$ & 16 & 1 & 0 & 0 & Completou \\
\hline S55 & 1074 & 14:59:01 & $15: 25: 23$ & $00: 26: 22$ & 0 & 0 & 0 & 0 & $\begin{array}{l}\text { Saiu da } \\
\text { página }\end{array}$ \\
\hline
\end{tabular}

Tabela 3. Estados de ânimo consolidado

\begin{tabular}{|c|c|c|c|c|c|c|}
\hline Aluno & Reg. & Momento & $\begin{array}{c}\text { Animado } \\
\text { Quadrante I) }\end{array}$ & $\begin{array}{c}\text { Desanimado } \\
\text { (Quadrante II) }\end{array}$ & $\begin{array}{c}\text { Insatisfeito } \\
\text { (Quadrante III) }\end{array}$ & $\begin{array}{c}\text { Satisfeito } \\
\text { (Quadrante IV) }\end{array}$ \\
\hline S53 & 1071 & 1 & 0,00 & 0,00 & 0,00 & 1,00 \\
\hline S53 & 1071 & 2 & 0,00 & 0,00 & 0,00 & 1,00 \\
\hline S53 & 1071 & 3 & 0,75 & 0,00 & 0,00 & 0,75 \\
\hline S54 & 1070 & 1 & 0,75 & 0,00 & 0,00 & 0,75 \\
\hline S54 & 1070 & 2 & 0,00 & 0,00 & 0,00 & 0,88 \\
\hline S54 & 1070 & 3 & 1,00 & 0,00 & 0,00 & 1,00 \\
\hline S55 & 1072 & 1 & 1,00 & 0,00 & 0,00 & 0,75 \\
\hline S55 & 1072 & 2 & 1,00 & 0,00 & 0,00 & 1,00 \\
\hline S55 & 1072 & 3 & 0,00 & 0,00 & 0,00 & 1,00 \\
\hline
\end{tabular}

Tabela 4. Valores calculados para o padrão comportamental

\begin{tabular}{|c|c|c|c|c|}
\hline Aluno & Registro & Confiança & \multicolumn{1}{|l|}{ Esforço } & Independência \\
\hline S53 & 1071 & 1 & 5 & 9 \\
\hline S54 & 1070 & 2 & 4 & 9 \\
\hline S55 & 1072 & 1 & 5 & 9 \\
\hline
\end{tabular}

Tabela 5. Valores normalizados no processo de sumarização.

\begin{tabular}{|r|c|c|c|c|c|}
\hline Alun & Sentenç: & $\begin{array}{c}\text { Animado } \\
\text { (Quadrante I }\end{array}$ & $\begin{array}{c}\text { Desanimado } \\
\text { (Quadrante II }\end{array}$ & Insatisfeito (Quadrante III & $\begin{array}{c}\text { Satisfeito } \\
\text { (Quadrante IV }\end{array}$ \\
\hline S53 & 0 & 0,00 & 0,00 & 0,00 & 0,00 \\
\hline S54 & 1 & 0,50 & 0,00 & 0,00 & 0,00 \\
\hline S55 & 1 & 0,00 & 0,00 & 0,00 & 0,50 \\
\hline S55 & 2 & 0,00 & 0,00 & 0,25 & 0,00 \\
\hline S55 & 3 & 0,00 & 0,00 & 0,00 & 0,00 \\
\hline
\end{tabular}


Para criar a RBD foi utilizado o software Hugin Lite v. 7.1 que representa graficamente as relações de dependências entre as variáveis e as probabilidades causais, proporcionando a dedução de uma ocorrência, dada a incerteza do domínio de estudo. Com o resultado apresentado pelo software pode-se verificar como os traços de personalidade influenciam nos padrões comportamentais que, por sua vez, tem ascendência nos estados de ânimo do aluno. A Tabela 6 exemplifica a submissão dos dados captados da amostra na RBD desenvolvida (baseada na Figura 3). Comparando-se os dados do autorelato e os obtidos através da RBD, verifica-se que os estados de ânimo encontrados nos alunos S54 e S55 se confirmaram. Entretanto, houve uma discordância forte com relação ao estado de satisfação do aluno S53 apresentado na RBD em relação ao autorelato.

Tabela 6. Resulatos obtidos na propagação dos dados da amostra em análise

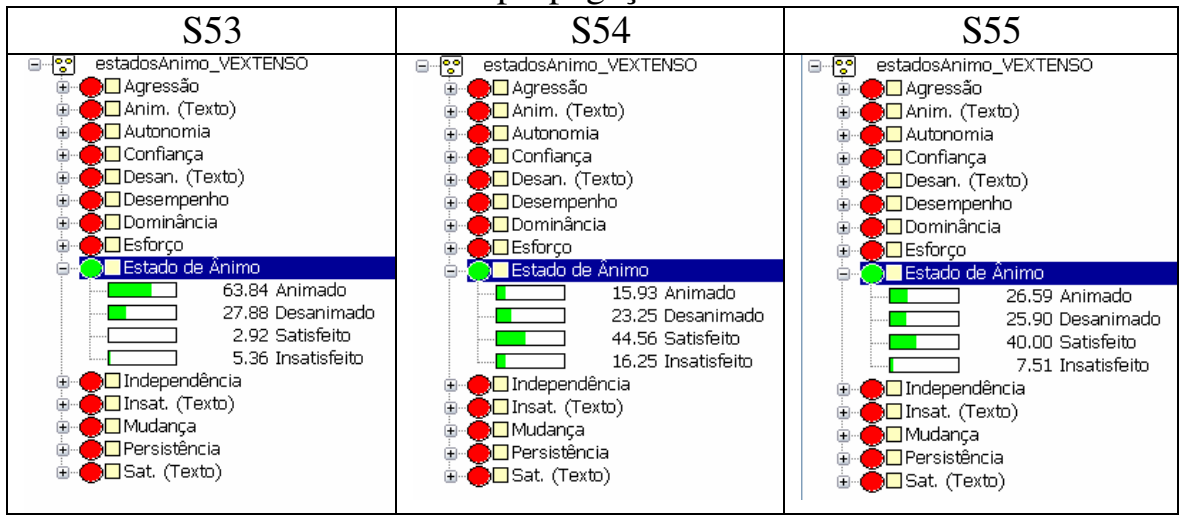

\section{Considerações Finais}

Este artigo descreve o processo de investigação para compreender se e quais aspectos afetivos podem ser reconhecidos a partir de dados registrados nas tecnologias digitais utilizadas no processo de ensino e aprendizagem. Decidiu-se por tratar o fenômeno afetivo estado de ânimo, por constituir aspecto mais representativo do cotidiano acadêmico e escolar. Esta investigação envolveu quatro etapas: 1) fundamentação teórica; 2) construção e validação do objeto de aprendizagem; 3) aplicação do instrumento IFP e do objeto em disciplina da Ciência da Computação (UFRGS); e 4) a construção da RBD, remodelação e análise dos resultados.

Naturalmente, o tamanho da amostra é muito pequeno. Parte-se, para análise de uma amostra com 85 sujeitos que já realizaram a atividade construção de algoritmos. Há necessidade de verificar a possibilidade de viés estatístico e confirmar as correlações intuitivamente consideradas.

O software Hugin é uma ferramenta interessante para a análise das probabilidades. Entretanto, a correlação entre variáveis deve ser bem entendida, e as tabelas de probabilidade condicionais associadas devem ser bem organizadas. No estudo de caso, os valores da tabela de probabilidade do nó estado de ânimo foram gerados aleatoriamente, o que pode explicar eventuais distorções.

\footnotetext{
Notas

${ }^{1}$ Os AVAs também são conhecidos por ambientes virtuais de ensino e aprendizagem (AVEA)

${ }^{2}$ Informações sobre a Universidade Aberta do Brasil podem ser encontradas em http://uab.capes.gov.br/

${ }^{3}$ Assim denominado em decorrência do trabalho De Anima de Aristóteles (2006) que trata da teoria geral do conhecimento ao considerar não só a natureza e os princípios do intelecto, mas também as emoções.

${ }^{4} \mathrm{O}$ "K" está relacionado ao assunto Construção de Algoritmos.

${ }^{5}$ Núcleo de Tecnologia Digital aplicada à Educação. Trata-se de um grupo de pesquisa do CNPq, ligado à Faculdade de Educação e ao CINTED - Centro Interdisciplinar de Novas Tecnologias http://www.nuted.edu.ufrgs.br.
} 
${ }^{6}$ O instrumento IFP (Inventário Fatorial da Personalidade), elaborado por Pasquali et alli (1997), avalia 15 necessidades ou fatores psicológicos, a saber: assistência, intracepção, afago, deferência, afiliação, dominância, denegação, desempenho, exibição, agressão, ordem, persistência, mudança, autonomia e heterossexualidade.

${ }^{7}$ Os alunos dispostos a participar da pesquisa assinam um termo de consentimento autorizando a coleta de dados.

${ }^{8} \mathrm{O}$ escore do sujeito é expresso em termos de percentil, isto é, número que indica quantos por cento de todos os sujeitos da população já analisada estão abaixo dele.

${ }^{9}$ A tokenização é uma técnica que decompõe o texto em termos separados por espaços, vírgulas, pontos, quebra de linhas, tabulações, etc.

${ }^{10}$ Stopwords são palavras consideradas irrelevantes para o contexto de pesquisa (artigos, preposições, etc).

\section{Referências Bibliográficas}

BEHAR, P. A.; WALQUIL, M.; BERNARDI, M; MORESCO, S. Refletindo sobre uma metodologia de pesquisa para AVA's. In: Congresso Internacional de Qualidade de Educação a Distância, 2005, São Leopoldo. Anais. São Leopoldo: Unisinos, v. 1. 2005.

BERCHT, M.. Em Direção a Agentes Pedagógicos com Dimensões Afetivas. Instituto de Informática. UFRGS. Tese de Doutorado. Porto Alegre. 2001.

DAVIDSON, R. J. (1994). On emotion, mood and related affective constructs. In P. Ekman \& R. J. Davidson (Eds.), The nature of emotion (pp. 51-55). Oxford, England: Oxford University Press. DOS SANTOS, A. I. O conceito de abertura em EAD. In: Mitto, F. M. \& Formiga, M. (Org.) Educação a Distância: o estado da arte. São Paulo: Pearson Education do Brasil, 2009.

EYNDE, P. O. T; DE CORTE, E., \& VERSCHAFFEL, L. Students'emotions : a key component of self-regulated learning? In: Schutz, P. A., \& Pekrun, R (Ed.), Emotion in Education (pp. 185204). Oxford, UK: Academic Press in Educational Psychology Series. 2007.

JAQUES, P. A.; LEHMANN, M. ; PESTY, S. (2009) Evaluating the Affective Tactics of an Emotional Pedagogical Agent. In: ACM Symposium on Applied Computing - Human Computer Interaction Track, 2009, Hawai. New York: ACM, 2009. v. 1. p. 104-109.

KANTROWITZ, M. Method and apparatus for analyzing affect and emotion in text. U.S. Patent 6622140 B1, 2003. Patent filed in September 2003.

PASQUALI, L.; AZEVEDO, M. M. \& GHESTI, I. (1997) Inventário Fatorial de Personalidade: manual técnico e de aplicação. São Paulo: Casa do Psicólogo.

PASQUALOTTI, P. R. Reconhecimento de expressões de emoções na interação mediada por computador. Computação Aplicada. UNISINOS, Dissertação de Mestrado. São Leopoldo, 2008.

PICARD, R. W. Affective Computing. Cambridge: MIT Press. 1997.

RODRIGUES, L. M. L. \& CARVALHO, M. STI-I: Sistemas Tutores Inteligentes que Integram Cognição, Emoção e Motivação. In: Revista Brasileira em Informática na Educação, v. 13, no 1, p. 20-34, RBIE, 2005.

SCHERER, K. R. Appraisal Considered as a Process of Multilevel Sequential Checking. In Scherer, K.R., Schorr, A., \& Johnstone, T., (Eds) Appraisal Processes in Emotion: Theory Methods, Research. Oxford, New York: Oxford University Press, 92-129. 2001.

SCHERER, K. What are emotions? And how can they be measured? In: Social Science Information 44 (4), 695-729. 2005.

SCHERER, K. R., \& TRAN, V. Effects of emotion on the process of Organization Learning. In I. Nonaka (Ed.), Handbook of organizational learning and knowledge (pp. 369-392). Oxford, UK: Oxford University Press. 2001.

SCHUTZ, P. A., \& PEKRUN, R. Introduction to emotion in education. In: Schutz, P. A., \& Pekrun, R (Ed.), Emotion in Education (pp. 3-10). Oxford, UK: Academic Press in Educational Psychology Series. 2007.

SERRES, M. Filosofia mestiça. Rio de Janeiro: Nova Fronteira, 1993.

SOLDATO, T., \& BOULAY,B. Implementation of Motivational Tactics in Tutoring Systems. Journal of Artificial Intelligence in Education, Charlottesville,v.6, p.337-378, 1995.

TRAN, V. The influence of emotions on decision-making processes in management teams. (L'influence des Emotions sur les Processus de Prise de Décision dans les Equipes de Cadres). Faculte De Psychologie et des Sciences de l'Education. Université de Genève. Thèse No 323. 2004. 